\title{
Results of anti-Toxoplasma gondii IgG, IgM, IgA and IgG Avidity testing in pregnant women in Rome, Italy
}

\author{
Carla Nisii', Stefania Pane', Giuseppina Liuzzi², Ornella Butera', Roberta Chiappini', \\ Daniele Khouri', Antonino Di Caro' \\ I Laboratory of Microbiology and Biorepository, “L. Spallanzani” National Institute for Infectious Diseases, 00 I 49 Rome, Italy \\ 2 Clinical Department, “L. Spallanzani” National Institute for Infectious Diseases, 00 I 49 Rome, Italy
}

Key words: Toxoplasma gondii, CLIA, ELISA

Risultati della ricerca di IgG, IgM e IgA anti-Toxoplasma gondii e test per l'avidità delle IgG in donne in gravidanza a Roma, Italia

\section{SUMMARY}

To evaluate the incidence of Toxoplasma gondii infection, the detection of specific $\lg$, $\lg M$, $\lg A$ and $\lg G$ avidity was performed on 1424 pregnant women referred to the "L. Spallanzani" Hospital in Rome (Italy). Of the I424 women screened, 20 (I.40\%) were likely to have been recently infected (presence of IgM/lgA, and/or low IgG avidity), 29 (2.04\%) had positive IgM coupled with high IgG avidity, 7 (0.49\%) had an unspecific result for IgM alone, 1339 (94.0\%), were negative for both $\lg$ and $\operatorname{lgM}, 29$ (2.04\%) showed evidence of past infection (IgG positive, IgM negative, high lgG avidity). In Conclusion our results underscore the importance of efficient antenatal screening and appropriate treatment for Toxoplasma infection in Italy.

\section{INTRODUCTION}

Toxoplasmosis, a cosmopolitan zoonotic disease caused by the intracellular parasite Toxoplasma gondii (T. gondii), is usually acquired through the ingestion of raw or undercooked meat containing viable tissue cysts or by exposure to soil, food, or water contaminated with oocysts excreted in the feces of cats or other felines infected with the parasite (3). The infection can also be transmitted vertically from an infected woman to a fetus during pregnancy $(1,2,11,13,14)$. An acute infection in pregnant women is associated with a range of outcomes from subclinical infection to intrauterine death. The severity of disease depends on the gestational age at transmission: the earlier the infection is, the more severe is the damage to the unborn child $(8,9)$. Damage to the central nervous system (cerebral calcification, hydrocephalus, microcephaly) and choroidoretinitis accounts for most of the nonfatal morbidity. The newborn often has a low birth weight, enlarged liver and spleen, jaundice, anemia, petechiae, and eye damage evidenced by of inflammation of the retina. Children who are apparently normal at birth may subsequently develop toxoplasmosis-associated injuries (15).

The prevalence of Toxoplasma infection in humans is related to several factors, including nutritional habits, contact with soil, age, and rural or urban settings. In this study, we evaluate the incidence of $T$. gondii infection in a population of 1424 pregnant women referred to the "L. Spallanzani" Hospital in Rome (Italy), for serological screening.
Table I. Serological results for serum samples from pregnant women referred to the “L. Spallanzani” Hospital in Rome (Italy).

\begin{tabular}{|c|c|c|c|c|c|}
\hline $\begin{array}{c}\text { Patient } \\
(\mathrm{n}=1424)\end{array}$ & $\begin{array}{c}\text { IgG titer } \\
\text { (equivocal } \\
\text { range:7.2-8.8 } \\
\text { IU/mL) }\end{array}$ & $\begin{array}{c}\text { IgM titer } \\
\text { (equivocal } \\
\text { range:6-8 } \\
\mathrm{AU} / \mathrm{mL})\end{array}$ & $\begin{array}{c}\text { IgA titer } \\
\text { (equivocal } \\
\text { range:4.0- } \\
\text { I6.0 AU/mL) }\end{array}$ & $\begin{array}{c}\text { IgG Avidity } \\
\text { index } \\
\text { (equivocal } \\
\text { range:0.30- } \\
0.40)\end{array}$ & Interpretation \\
\hline 20 & $\geq 8.8$ & $\geq 8$ & $>16.0$ & Low & $<16$ weeks \\
\hline 29 & $\geq 8.8$ & $\geq 8$ & $\leq 4.0-16.0$ & High & $>16$ weeks \\
\hline 7 & $<7.2$ & $6.0-\geq 8$ & $<4.0$ & ND & $\begin{array}{c}\text { Unspecific } \\
\text { IgM }\end{array}$ \\
\hline 29 & $\geq 8.8$ & $<6$ & $<4.0$ & High & Past infection \\
\hline 1339 & $<7.2$ & $<6$ & & ND & Negative \\
\hline
\end{tabular}

\section{MATERIALS AND METHODS}

Serological screening for Toxoplasma infection was performed on 1424 pregnant women from October 2010 to October 2011.

Samples were analysed by use of a chemiluminescence assay (CLIA) for the detection of IgG, IgM and IgG avidity

\section{Corresponding author: Pane Stefania}

Laboratorio di Microbiologia e Banca Biologica, Istituto Nazionale per le Malattie Infettive Via Portuense 292, 00149 Roma - Tel.: 0655170688

E-mail: stefania.pane@inmi.it 
(LIAISON® Toxoplasma gondii, Diasorin, Saluggia, Italy), and a capture ELISA for detecting IgA antibodies. Clinical and demographic data such as age, time of pregnancy, and nationality were recorded for each patient.

\section{RESULTS}

Of the 1424 women screened, $20(1.40 \%)$ were likely to have been recently infected with $T$. gondii (presence of $\operatorname{IgM} / \operatorname{IgA}$, and/or low $\operatorname{IgG}$ avidity), $29(2.04 \%)$ had positive IgM coupled with high IgG avidity, $7(0.49 \%)$ had an unspecific result for IgM alone, $1339(94.0 \%)$ were negative for both $\mathrm{IgG}$ and $\mathrm{IgM}$, while the remaining patients $(29,2.04 \%)$ showed evidence of past infection ( $\operatorname{IgG}$ positive, IgM negative, high $\mathrm{IgG}$ avidity). Following the first test, 7 patients with an IgM-positive test result were followed-up over the following months, and results did not show evidence of IgG seroconversion. Eight of the 20 women recently infected were in the first trimester of pregnancy, their median age is 36 years (range 28 - 42 years) and all women were born in Italy, except two. The remainder were on the second month of pregnancy.

\section{DISCUSSION}

In Europe, congenital toxoplasmosis affects between 1 and 10 in 10000 newborn babies (4) of whom $1-2 \%$ develop learning difficulties or die and $4-27 \%$ develop retinochoroidal lesions leading to permanent unilateral impairment of vision $(5,7)$. The prevalence of previous Toxoplasma infection in pregnant women ranges from $10 \%$ in the United Kingdom to around 55\% in France and Greece; in many countries it has declined sharply over the past three decades (2). The decline in prevalence of infection reflects that a woman during pregnancy might be more conscious about avoiding potential sources of infection, such as eating undercooked meat and contact with contaminated soil. Our results show that a total of $5.47 \%$ (78 out of 1424) of pregnant women screened at our hospital showed evidence of past or present Toxoplasma infection, underscoring the importance of efficient ante-natal screening and appropriate treatment for Toxoplasma infection in Italy.

\section{REFERENCES}

1. Berrebi A, Bardou M, Bessieres MH, et al. Outcome for children infected with congenital toxoplasmosis in the first trimester and with normal ultrasound findings: a study of 36 cases. Eur J Obstet Gynecol Reprod Biol 2007; 135 (1): 53-7.

2. Cook AJ, Gilbert RE, Buffolano W, et al. Sources of Toxoplasma infection in pregnant women: European multicentre case-control study. European Research Network on Congenital Toxoplasmosis. BMJ 2000; 321 (7254): 142-7.

3. Dubey JP. The history of Toxoplasma gondii - the first 100 years. J Eukaryot Microbiol 2008; 55 (6): 467-75.

4. Gilbert RE. Epidemiology of infection in pregnant women. In: Petersen E, Amboise-Thomas P, eds. Congenital toxoplasmosis: scientific background, clinical management and control. Paris: Springer-Verlag France, 1999.

5. Guerina NG, Hsu HW, Meissner HC, et al. Neonatal serologic screening and early treatment for congenital Toxoplasma gondii infection. The New England Regional Toxoplasma Working Group. N Engl J Med 1994; 330 (26): 1858-63.

6. Jenum PA, Stray-Pedersen B. Developments of specific immunoglobulins G, M, and A following primary Toxoplasma gondii infection in pregnant women. J Clin Microbiol 1998; 36 (10): 2907-13.

7. Lebech M, Andersen O, Christensen NC, et al. Feasibility of neonatal screening for Toxoplasma infection in the absence of prenatal treatment. Danish Congenital Toxoplasmosis Study Group. Lancet 1999; 353 (9167): 1834-7.

8. Montoya JG, Liesenfeld O, Toxoplasmosis. Lancet 2004; 363 (9425): 1965-76.

9. Montoya JG, Rosso F. Diagnosis and management of toxoplasmosis. Clin Perinatol 2005; 32 (3): 705-26.

10. Petersen E, Borobio MV, Guy E, et al. European multicentric study of the Liason automated diagnostic system for determination of Toxoplasma gondii specific immunoglobulin $\mathrm{G}(\mathrm{IgG})$ and IgM and the IgG avidity index. J Clin Microbiol 2005; 43: 1570-4.

11. Rorman E, Zamir CS, Rilkis I, Ben-David H. Congenital toxoplasmosis - prenatal aspects of Toxoplasma gondii infection. Reprod Toxicol 2006; 21 (4): 458-72.

12. Schinella M, Turci V. La sierologia del complesso TORCH. Applicazioni ed Interpretazioni. Med Lab 1998; 2: 156-9.

13. Sensini A. Toxoplasma gondii infection in pregnancy: opportunities and pitfalls of serological diagnosis. Clin Microbiol Infect 2006; 12: 504-12.

14. Singh S. Mother-to-child transmission and diagnosis of Toxoplasma gondii infection during pregnancy. Indian J Med Microbiol 2003; 21 (2): 69-76.

15. Wilson CB, Remington JS, Stagno S, Reynolds DW. Development of adverse sequelae in children born with subclinical congenital Toxoplasma infection. Pediatrics 1980; 66: 767-74. 